\title{
Tonic immobility in the zebra shark, Stegostoma fasciatum, and its use for capture methodology
}

\author{
Michael J. Williamson (iD • Christine Dudgeon • \\ Robert Slade
}

Received: 18 September 2017 / Accepted: 19 January 2018 / Published online: 2 February 2018

(C) The Author(s) 2018. This article is an open access publication

\begin{abstract}
When conducting biological investigations on shark species, capture and brief restraint procedures may be required in order to collect ecological, behavioral and physiological data. Tonic immobility is an innate, reversible, coma-like stasis displayed by a large number of taxa, including sharks, and has been used for brief restraint, but is rarely used during capture itself. Here, we present a novel, non-lethal capture method of zebra sharks, Stegostoma fasciatum, using tonic immobility, in the field. Zebra sharks were caught by free diving, and on SCUBA, inducing a state of tonic immobility by quickly applying tight-fisted manual pressure to the caudal fin, instead of the dorso-ventral inversion method. Divers were then able to collect tissue samples for genetic analysis, and in some cases, maintain the animals in a state of
\end{abstract}

\footnotetext{
M. J. Williamson $(\bowtie)$

Department of Geography, Kings College London, Strand Campus, London WC2R 2LS, UK

e-mail: michael.williamson.17@ucl.ac.uk
}

\section{J. Williamson}

Institute of Zoology, Zoological Society of London, Regent's Park, London NW1 4RY, UK

\section{Dudgeon}

School of Biomedical Sciences, The University of Queensland, St Lucia, QLD 4072, Australia

\section{R. Slade}

Kingscliff, NSW 2487, Australia

M. J. Williamson

Department of Geography, University College London, Pearson Building, Gower Street, London WC1E 6BT, UK tonic immobility during transport up to the research vessel for additional data collection. Decreased duration of anthropogenic intervention, and minimal physical struggle associated with this capture and restraint method is expected to reduce physiological markers of distress. Tonic immobility induction and other methods of nonlethal capture deserve continued investigation.

Keywords Zebra sharks · Tonic immobility · Capture · Restraint · Tagging

\section{Introduction}

Over the past half century there has been a dramatic increase in worldwide catches of shark species (Baum et al. 2003; Burgess et al. 2005). As such, management of shark populations has emerged as an important conversation priority (Godin and Worm 2010). The relatively recent development of methodologies, such as acoustic and satellite telemetry and time depth recorders, have increased our knowledge of migration, distribution and population dynamics in shark populations (Heithaus et al. 2001; Voegeli et al. 2001; Hammerschlag et al. 2011; Dudgeon et al. 2013). In order to implant tags to collect biological and movement data on shark populations, capture of target species is usually required. Longline and drumline capture are the most frequent methods used. However, although both techniques are potentially less stressful than some other capture methods, they may still result in captured animals struggling dramatically and thrashing violently (Brooks et al. 2012), which can 
lead to potentially lethal physiological consequences (Hoffmayer and Parsons 2001; Manire et al. 2001; Skomal 2007; Mandelman and Skomal 2008). As such, there is a need for the exploration of other non-lethal methods of capture of shark species, which cause less impact to the stress and welfare of captured animals (Barnett et al. 2010).

When capture and restraint is undertaken on wildlife, tonic immobility is often used as a method of calming or sedating the animal. Tonic immobility is an innate, reversible, coma-like stasis displayed by a large number of wildlife taxa (Gallup 1974; Hennig et al. 1979; Thompson et al. 1981; Wells et al. 2005). It is characterized by a reversible catatonic motionless posture, immobility, and an unresponsiveness to noxious or injurious stimulation. Tonic immobility causes muscle hypertonicity in terrestrial vertebrates but relaxed muscle tone and a 'limp' posture develops in fish species (Thompson et al. 1981; Whitman et al. 1986; Wells et al. 2005; Marx et al. 2008; Brooks et al. 2011). Tonic immobility can be induced by several stimuli, but external pressure and physical restraint are the most common (Bayard 1957; Jones 1986).

Tonic immobility is frequently used in both wildlife research and aquarium husbandry to sedate shark species during restraint and limit injury to both the animal and personnel (Henningsen 1994; Holland et al. 1999; Brooks et al. 2011). Tonic immobility has been found in multiple shark species but the onset and length of induction can be variable from species to species (Henningsen 1994; Brooks et al. 2011), and not all shark species can be induced into tonic immobility (Henningsen 1994). The function of tonic immobility in sharks is currently unknown, however, it has been reported in several shark species during courtship. As such, it may act as a mechanism to invoke female acquiesence during mating rituals (Pratt and Carrier 2001; Kunze and Simmons 2004; Brunnschweiler and Pratt Jr 2008), as well as having a role in anti-predator responses. In those shark species that do show tonic immobility it is usually induced by rapid dorso-ventral inversion (Watsky and Gruber 1990), but can also be induced by pumping water into the branchial chamber (Wells et al. 2005). In zebra sharks, Stegostoma fasciatum, tonic immobility can be induced not only by dorso-ventral inversion, but also by applying pressure to the distal end of the tail (Henningsen 1994; Dudgeon et al. 2013), and usually occurs immediately following pressure. This is used in courtship where males, after following females, bite the distal end of the tail, causing the female to be induced into a catatonic state (Kunze and
Simmons 2004; Brunnschweiler and Pratt Jr 2008) (Fig. 1.).

The zebra shark, is a medium-sized (maximum length $2.5 \mathrm{~m}$ ) member of the order Orectolobiformes (carpet sharks) and is found throughout shallow coastal waters of the tropical and subtropical Indo-West Pacific (Last and Stevens 2009). In order to obtain information on population genetics and movement behavior in zebra sharks along the east coast of Australia, the use of the zebra shark's natural tonic immobility reaction was used to capture individuals for acoustic tag implantation and tissue sampling. Here, a novel method of non-lethal capture for a shark species is described. This method provides a quick, efficient way of capturing zebra sharks in order to gather information on distribution, genetics, abundance and population dynamics of the species.

\section{Materials and methods}

Study site

Capture was undertaken around a rocky reef structure, known as The Group (153 $\left.32.844^{\prime} \mathrm{E}, 27^{\circ} 25.378^{\prime} \mathrm{S}\right)$, located approximately $500 \mathrm{~m}$ offshore from North Stradbroke Island, southeast Queensland, Australia. The area comprises a series of large submerged rocks separated by sand patches and lined by a sand gutter in water depths of 5-18 m. Zebra sharks form aggregations at The Group around November each year when the water temperature reaches $22{ }^{\circ} \mathrm{C}$. There is no clear end to this aggregation period with individuals still present during April and May months (Dudgeon et al. 2013). A

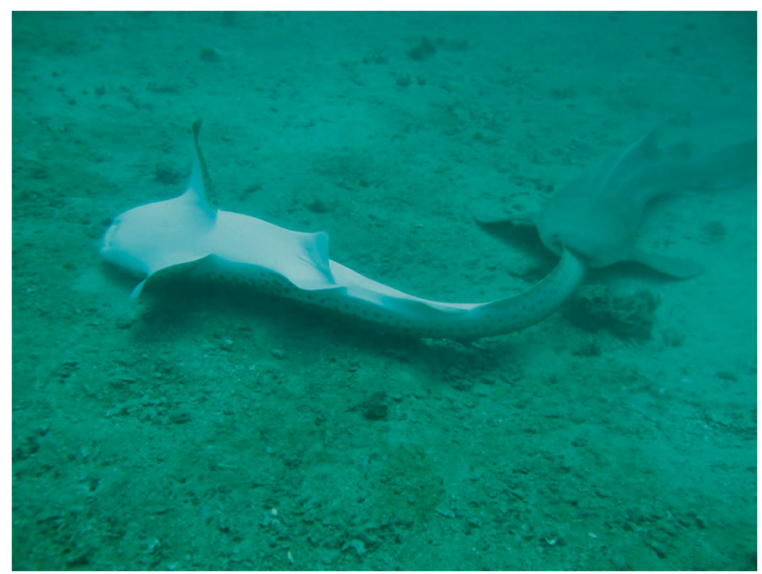

Fig. 1 Male zebra shark, biting tail of female during courtship, inducing tonic immobility 
population of around 460 individuals is thought to visit The Group seasonally (Dudgeon et al. 2008). The reason for these aggregations is unclear, and although precopulatory behavior has been observed at the site, no copulation events or other mating behavior has been observed (Dudgeon et al. 2008).

\section{Tail grab procedure}

The initial capture technique was to free-dive to sharks (either swimming in the water column, or stationary on the bottom) and grab them by the pectoral fins and wrestle them to the surface. One of the authors (RS) received advice from a local diver that this species of shark could be grabbed by the tail, upon which the animal would remain still and could be easily pulled to the surface. The tail-grab technique had three principal advantages: (i) an assumption of less stress on the animal, (ii) less stress on the capturer, and (iii) the ability to use the technique while on SCUBA allowing divers to work on the animal in situ.

Zebra shark captures were undertaken in calm conditions, wind speed of $<15$ knots, with swell less than $2 \mathrm{~m}$. The best location to induce tonic immobility in the zebra shark is the distal end of the caudal fin (see Figs. 1 and 2). Firm pressure, by grabbing the end of the tail and making a tight fist is required. Immobility is induced almost immediately after pressure is applied to the tail, the animal relaxes and may remain in position or rotate dorsoventrally (see Figs. 1 and 2). Pressure should be maintained on this point to keep the animal in tonic immobility. Individual sharks may suffer damage to

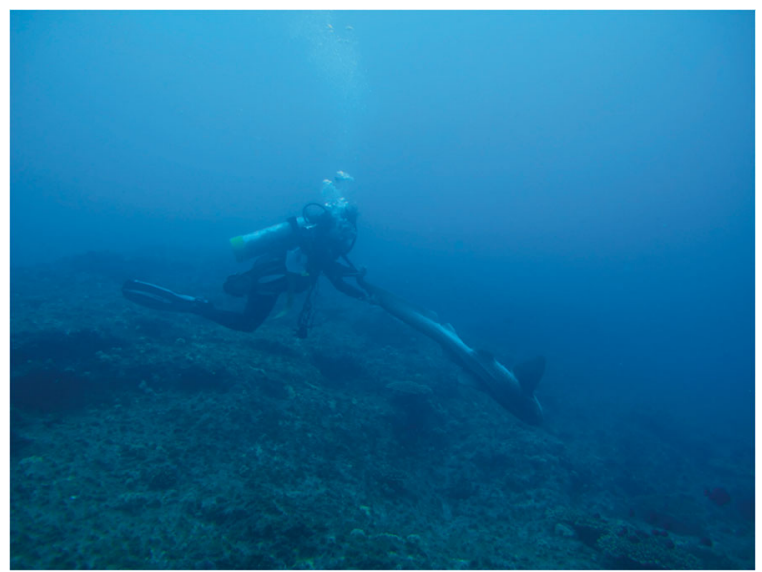

Fig. 2 Example of tail-grab technique on SCUBA inducing tonic immobility in a zebra shark the tail, as it is likely to be the focus of predation attempts (Fig. 3). However, this technique has been successful even in those animals which have suffered damage to the caudal fin.

Captures of zebra sharks by free diving typically took less than $5 \mathrm{~min}$, from locating a zebra shark, to capture, to procedures on, or alongside, the vessel. Teams of two people snorkelled around the group, searching for resting or moving individuals. After locating a zebra shark, one of the team would free dive to the resting or swimming shark and grab the distal end of the tail to induce tonic immobility. The shark was then towed to the surface by the free diver. At the surface, the second team member would assist by hugging the shark around its pectoral fins, with the first team member still applying pressure to continue to induce tonic immobility. Individuals with significant diving and snorkelling experience were used in capture teams. When training new individuals in this technique, the new team member would first observe captures from the vessel. All new team members would have to show proficient swimming ability to be trained in the capture technique. When the technique was understood, the new member would initially be the 'second' team member, before graduating to diving for a shark.

Zebra sharks at depths deemed too deep (>12 m) for free diving were captured by SCUBA. Capture times on SCUBA were longer than free diving, but were typically less than ten minutes long. A team of two divers would approach a resting or swimming shark from behind. One diver would grab the distal end of the tail to induce tonic immobility (Fig. 2), the individual then placed in a large diving bag and an appropriate ascent, with rest stop, was

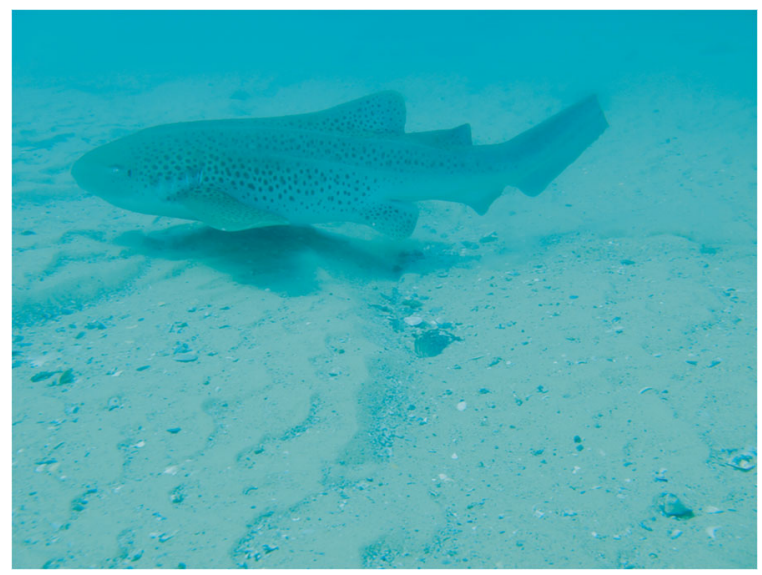

Fig. 3 Example of tail damage, possibly from predation, on an adult zebra shark 
made. Only experienced SCUBA divers were used during this capture technique. This tail-grab technique was also used to obtain tissue samples from the zebra sharks for genetic studies. This was either taken on board during tagging implantation procedures, or as a separate process on SCUBA. Tissue sampling on SCUBA typically took no more than $90 \mathrm{~s}$. Resting or swimming sharks that were not brought to the surface for tag implantation were restrained by tail-grabbing by the SCUBA diver while a small tissue sample was removed at the tail end by using a cattle ear notcher (for methodology see Dudgeon et al. 2009).

\section{Restraint and release}

Tonic immobility often ceased when the shark reached the surface and the animal would start to struggle and fight. The second team member would control any struggling by holding the shark around the pectoral fins. In some cases a third person was needed to help guide the individual and the divers to the vessel. The research vessel was not anchored during the capture procedures as currents and waves could pose significant difficulties for the capture team transporting the shark on the surface. Instead, one person would act as a surface spotter in the water and signal the vessel when the shark had been captured. The vessel would then be positioned down current within $20 \mathrm{~m}$ of the capture team and motors placed into neutral, to reduce surface distance and swimming against current.

Sharks were manoeuvred to the vessel for tag implantation and biological measurements (for methodology see Barnett et al. 2011). These were undertaken either in a stretcher by the side of the vessel, or on deck. Pressure on the distal end of the tail was maintained throughout all capture and handling procedures to attempt to keep the animal in tonic immobility for as long as possible. If procedures were undertaken on a stretcher, a Velcro strap and line was attached to upper part of the tail and fixed to the vessel. Alternatively, sharks were inverted dorso-ventrally on the vessel deck to induce tonic immobility, as well as pressure applied to the caudal fin. Animals tended to remain in tonic immobility throughout this process, with rare bouts of struggling, lasting no more than ten seconds, occuring. During these bouts, the animal was restrained and tagging procedures temporarily halted until the animal relaxed once more. Zebra sharks are active buccal pumpers, and, as such, when tag implantation and biological measurements were undertaken on the stretcher by the side of the vessel, no buccal pump was used. The animal was kept submerged and facing into the current. However, if procedures were carried out on deck, a specialized buccal pump (a modified bilge pump) was used at all times to facilitate sea water moving over the gills and the animal's head and eyes were covered with a towel soaked in sea water. While tag implantation and biological measurements were taken, one person would monitor the individual for any signs of stress (restlessness, reddening of the skin), and, if on deck, kept the animal cool by slowly pouring buckets of sea water over the shark. When procedures were finished, the shark was re-righted, and held in the water for $30 \mathrm{~s}$ before release. One person snorkelled after the released shark to observe any potential signs of injury or distress.

\section{Results}

Between 2004 and 2013, 30 individuals were implanted with acoustic tags and 119 captured for genetic sampling. Of these 30 captures for tag implantation 26 have been detected between 219 and 2618 days post-release by the fixed underwater array system, and/or by photo identification [see Dudgeon et al. (2008, 2013), unpublished data]. The duration of tonic immobility onset in this species was tested on three animals, which were tail grabbed and maintained in position for ten minutes while the capture team were on SCUBA. For sampling purposes animals were not held in immobility for any longer than needed to obtain tissue samples underwater or bring them to the surface for tagging. Total capture times were short, $(<5 \mathrm{~min}$ from capture to tag procedures being initiated when free diving, $<10 \mathrm{~min}$ on SCUBA, $<1 \mathrm{~min}$ when just genetically sampling an individual). Free diving captures and restraints were generally shorter than SCUBA, but mainly due to the time needed for ascension while on SCUBA.

All animals captured exceeded maturation size, and it is unknown whether this technique works on juvenile animals. Interestingly, both sexes were able to be induced into tonic immobility with this method with no obvious differentiation in reaction between the sexes. More females have been captured than males (e.g., for acoustic tag implantation 21 sharks were female and nine were male), but this is likely due to a higher proportion of females present at the research site. 
Individuals showed no signs of obvious stress or injury to capture procedures, swimming quickly and strongly following release. However, one individual animal took $10 \mathrm{~min}$ after release to swim away from the side of the vessel.

Not every capture attempt by tail grab was successful and further investigation of the success rate with this method is warranted. However, we can report the success would be above $90 \%$ (pers. comm. RS). No injuries occurred to any of the capture team members during the application of this technique.

\section{Discussion}

This investigation shows that a novel capture technique, using a natural tonic immobility reaction, can be used for successfully capturing zebra sharks, of both sexes, for tagging studies and biological investigations, with minimal negative impact to the animal. There can be significant variation between species in methods for the induction of tonic immobility (Bayard 1957; Gallup 1977), and to our knowledge no other shark species has been induced with this tail-grab technique. 149 individuals have been caught for both tag implantation and genetic sampling procedures, with no known causes of injury to either the target animal or personnel undertaking the capture procedure. Of the 30 sharks captured for acoustic tag implementation, 26 have been detected between 219 and 2618 days post-release by the fixed underwater array system, and/or by photo identification [see Dudgeon et al. (2008, 2013) unpublished data]. Four sharks were not recorded subsequently on fixed array stations or by photo identification. Following capture and surgery, the sharks were monitored and usually swam off quickly for a several seconds to a few minutes and then resumed normal swimming speed or resting behavior. It is not possible to determine why these four animals have not been detected, and any potential impact of the capture method. Other potential impacts include stress response to the tagging procedure, tag failure, external tag migration, tag fouling, failure of animals to swim near fixed arrays, as well as mortality due to predation or other causes.

This technique is most likely only suitable for benthic species. In addition, to reduce risk to the capturer, it's probably only suitable for non-aggressive species. However, it is currently unknown under what conditions this technique could be used to immobilise other species, either as a technique on its own or part of another capture methodology i.e., on species caught by net or by baited hook. The factors that may influence tonic immobility in zebra sharks were not tested for. However, given that tonic immobility seems to be associated with mating (i.e., male restraining female) in zebra sharks, and that tonic immobility invariably broke down within a few metres of the surface, there may be a both a hormonal and a pressure influence to this response. There appear to be two conditions that may reduce success of this technique - (i) a tail-grab of animals swimming in the water column compared with animals lying stationary on the bottom, and (ii) a slow grab of the tail compared with a quick and firm grab. With regard to the latter we assume that a prolonged touch of the tail prior to a grab is less effective than a quick grab. Although further investigation on the conditions that lead to success is warranted, nonetheless we feel that the information presented here is a valuable contribution and start.

This method is most advantageous due to its speed and limited-invasiveness to the animal. Longlines may be set between three and eight hours (Weng and Block 2004; Barnett et al. 2010; Brooks et al. 2012) and drumlines around one hour (Hammerschlag et al. 2012). This is considerably longer than the technique described here (between $60 \mathrm{~s}$ and ten minutes depending on sampling method). In addition, since no line or hooks are used in this technique, likelihood of injuries such as blood loss or entanglement are minimized. Potential issues with longline capture include hooking injuries from piercing or swallowing, as well as potential infection from opportunistic pathogens in subsequent wounds (Smith 1992). A lasso technique, where a heavy-duty rope is used to place a noose over an individual sharks caudal fin to capture an animal (Fitzpatrick et al. 2011; Otway 2015), has been used previously in order to avoid hooks and lines. However, this does not induce tonic immobility in the captured animal. Individuals will still thrash and struggle for significant periods as they are reeled in, leading to hyperactivity and exhaustive anaerobic exercise and potentially threatening conditions, such as capture myopathy (Hoffmayer and Parsons 2001; Manire et al. 2001; Skomal 2007; Mandelman and Skomal 2008).

However, the efficacy of this technique is reliant on the speed of procedure being undertaken on the animal, as it has been reported that tonic immbolity can be an inherently stressful experience, and one that increases 
with time (Brooks et al. 2011). In addition, very little is known of the physiology of tonic immobility in sharks. It is not currently known whether they feel pain or whether stress is actually reduced during tonic immobility. Minimizing impact is important not only for the welfare of an individual, but also to minimize the chances that research methods may affect an animal's behavior, which can influence the results of the research (Powell and Proulx 2003; Williamson et al. 2016). Further investigation therefore is needed in order to assess whether the use of tonic immobility is better for the stress and welfare of captured sharks opposed to other techniques. For example, examining secondary metabolites from blood samples from sharks caught using different techniques, as per Awruch et al. (2011).

To date no injury to personnel has been associated with this technique, however there are inherent risks with both free diving and SCUBA, such as hypoxia, pulmonary oedema, and 'shallow water blackout' (Bayne and Wurzbacher 1982; Strong et al. 1986; Wilks 2000; Lindholm and Lundgren 2009). Only experienced divers are used during capture efforts and snorkelers monitor from the surface during capture attempts. SCUBA is used when capture is undertaken in deeper waters. Despite inherent risks, as long as current protocols are adhered too, it is unlikely that this method is unsafe for any personnel undertaking it. However, this capture technique is only viable in areas where free-diving and SCUBA can be undertaken safely i.e., in coastal areas that are not effected by bad weather conditions (e.g., high winds, large swell), low in-water visibility and/or other inherent dangers that reduce underwater access.

The function of tonic immobility in zebra sharks has not been investigated. As biting of the tail and tonic immobility have been seen during mating rituals by zebra sharks (Kunze and Simmons 2004; Brunnschweiler and Pratt Jr 2008), tonic immobility may play a function in mating strategies. However, as it can be induced in both males and females, this also suggests an additional function, possibly anti-predatory. Zebra sharks are unique amongst shark species for having a very long, single-lobed caudal fin. The tail is a likely focus of predation attempts on marine species (Long and Jones 1996; Naessig and Lanyon 2004). Therefore, although the function for this long caudal fin is unknown, due to its length, it does pose a likely place for predation attempts. If, like in other taxa, tonic immobility functions as an anti-predator device, then pressure to the distal end of their long caudal fin would be an obvious place in zebra sharks for induction, as it may be the most likely place for predator attack (Fig. 3).

In conclusion, a non-lethal method for the capture of zebra sharks by inducing a tonic immobility response has been developed. However, its function in zebra sharks is unknown and there have been no other reports of tonic immobility being induced in this manner in other shark species. Induction of tonic immobility by applying pressure to the distal end of the tail may be unique to zebra sharks. This technique provides a viable alternative to other capture methods, such as longline and drumline, but relies on experienced divers and good environmental conditions. Due to the minimal capture time and lack of lines and hooks with this technique, the welfare and stress of individuals captured with this method should be lower than other current non-lethal methods of shark capture. As such, this method should be the preferred option when undertaking investigations on zebra sharks that require capture. However, examination of stress responses are required before it can be confidently used as a less-stressful alternative to other capture techniques. Due to the necessity of capture for biological investigations into shark species, further methods of non-lethal capture to shark should continue to be investigated and developed.

Acknowledgments This data and research would not have been possible without the hard work and assistance of volunteers. Particular thanks go to Jody Kreuger, Adam Barnett, Cynthia Awruch, Lydie Couturier, Ned van Dyck, and James Dowdeswell. Research was conducted with the ethical approval of the University of Queensland (Animal Ethics Committee approval \# SVS/ 323/11), and with permit approval from the Queensland Department of Primary Industries and Fisheries (General Fisheries Permit \#515490) and the Queensland Department of Environment and Resource Management (Moreton Bay Marine Park Permit \#QS2012/MAN153).

Open Access This article is distributed under the terms of the Creative Commons Attribution 4.0 International License (http:// creativecommons.org/licenses/by/4.0/), which permits unrestricted use, distribution, and reproduction in any medium, provided you give appropriate credit to the original author(s) and the source, provide a link to the Creative Commons license, and indicate if changes were made.

\section{References}

Awruch CA, Simpfendorfer C, Pankhurst NW (2011) Evaluation and use of a portable field kit for measuring whole-blood lactate in sharks. Mar Freshw Res 62:694-699 
Barnett A, Abrantes KG, Stevens JD, Semmens JM (2011) Site fidelity and sex-specific migration in a mobile apex predator: implications for conservation and ecosystem dynamics. Anim Behav 81:1039-1048

Barnett A, Redd KS, Frusher SD, Stevens JD, Semmens JM (2010) Non-lethal method to obtain stomach samples from a large marine predator and the use of DNA analysis to improve dietary information. J Exp Mar Biol Ecol 393:188-192

Baum JK, Myers RA, Kehler DG, Worm B, Harley SJ, Doherty PA (2003) Collapse and conservation of shark populations in the northwest Atlantic. Science 299:389-392

Bayard J (1957) The duration of tonic immobility in guinea pigs. J Comp Physiol Psychol 50:130

Bayne CG, Wurzbacher T (1982) Can pulmonary barotrauma cause cerebral air embolism in a non-diver? Chest 81:648-650

Brooks EJ, Mandelman JW, Sloman KA, Liss S, Danylchuk AJ, Cooke SJ, Skomal GB, Philipp DP, Sims DW, Suski CD (2012) The physiological response of the Caribbean reef shark (Carcharhinus perezi) to longline capture. Comp Biochem Physiol A Mol Integr Physiol 162:94-100

Brooks EJ, Sloman KA, Liss S, Hassan-Hassanein L, Danylchuk AJ, Cooke SJ, Mandelman JW, Skomal GB, Sims DW, Suski CD (2011) The stress physiology of extended duration tonic immobility in the juvenile lemon shark, Negaprion brevirostris (Poey 1868). J Exp Mar Biol Ecol 409:351-360

Brunnschweiler JM, Pratt HL Jr (2008) Putative male-male agonistic behaviour in free-living zebra sharks, Stegostoma fasciatum. Open Fish Sci J 1:23-27

Burgess GH, Beerkircher LR, Cailliet GM, Carlson JK, Cortés E, Goldman KJ, Grubbs RD, Musick JA, Musyl MK, Simpfendorfer CA (2005) Is the collapse of shark populations in the northwest Atlantic Ocean and Gulf of Mexico real? Fisheries 30:19-26

Dudgeon CL, Broderick D, Ovenden JR (2009) IUCN classification zones concord with, but underestimate, the population genetic structure of the zebra shark Stegostoma fasciatum in the Indo-West Pacific. Mol Ecol 18:248-261

Dudgeon CL, Lanyon JM, Semmens JM (2013) Seasonality and site fidelity of the zebra shark, Stegostoma fasciatum, in southeast Queensland, Australia. Anim Behav 85:471-481

Dudgeon CL, Noad MJ, Lanyon JM (2008) Abundance and demography of a seasonal aggregation of zebra sharks Stegostoma fasciatum. Mar Ecol Prog Ser 368:269-281

Fitzpatrick R, Abrantes KG, Seymour J, Barnett A (2011) Variation in depth of whitetip reef sharks: does provisioning ecotourism change their behaviour? Coral Reefs 30:569-577

Gallup GG (1974) Animal hypnosis: factual status of a fictional concept. Psychol Bull 81:836

Gallup GG (1977) Tonic immobility: the role of fear and predation. Psychol Rec 27:41

Godin AC, Worm B (2010) Keeping the lead: how to strengthen shark conservation and management policies in Canada. Mar Policy 34:995-1001

Hammerschlag N, Gallagher AJ, Lazarre DM (2011) A review of shark satellite tagging studies. J Exp Mar Biol Ecol 398:1-8

Hammerschlag N, Luo J, Irschick DJ, Ault JS (2012) A comparison of spatial and movement patterns between sympatric predators: bull sharks (Carcharhinus leucas) and Atlantic tarpon (Megalops atlanticus). PLoS One 7:e45958
Heithaus MR, Marshall GJ, Buhleier BM, Dill LM (2001) Employing Crittercam to study habitat use and behavior of large sharks. Mar Ecol Prog Ser 209:307-310

Hennig CW, Dunlap WP, Harston CT (1979) Tonic immobility and skin color in anoles: effects of serotonin precursors and metabolites. Physiol Behav 22:1079-1088

Henningsen AD (1994) Tonic immobility in 12 elasmobranchs: use as an aid in captive husbandry. Zoo Biol 13:325-332

Hoffmayer ER, Parsons GR (2001) The physiological response to capture and handling stress in the Atlantic sharpnose shark, Rhizoprionodon terraenovae. Fish Physiol Biochem 25:277-285

Holland NK, Wetherbee MB, Lowe GC, Meyer GC (1999) Movements of tiger sharks (Galeocerdo cuvier) in coastal Hawaiian waters. Mar Biol 134:665-673

Jones RB (1986) The tonic immobility reaction of the domestic fowl: a review. Worlds Poult Sci J 42:82-96

Kunze K, Simmons L (2004) Notes on reproduction of the zebra shark, Stegostoma fasciatum, in a captive environment. In: Smith M, Warmolts D, Thoney D, Hueter RE (eds) The elasmobranch husbandry manual: captive care of sharks, rays and their relatives. Ohio Biological Survey, Columbus, pp 493-497

Last PR, Stevens JD (2009) Sharks and rays of Australia. CSIRO Publishing, Melbourne

Lindholm P, Lundgren CE (2009) The physiology and pathophysiology of human breath-hold diving. J Appl Physiol 106: 284-292

Long DJ, Jones RE (1996) White shark predation and scavenging on cetaceans in the eastern north pacific ocean. In: Klimley AP, Ainley DG (eds) Great white sharks: the biology of Carcharodon carcharias. Academic Press, New York, pp 293-307

Mandelman JW, Skomal GB (2008) Differential sensitivity to capture stress assessed by blood acid-base status in five carcharhinid sharks. J Comp Physiol B 179:267-277

Manire C, Hueter R, Hull E, Spieler R (2001) Serological changes associated with gill-net capture and restraint in three species of sharks. Trans Am Fish Soc 130:1038-1048

Marx BP, Forsyth JP, Gallup GG, Fusé T, Lexington JM (2008) Tonic immobility as an evolved predator defense: implications for sexual assault survivors. Clin Psychol Sci Pract 15:74-90

Naessig PJ, Lanyon JM (2004) Levels and probable origin of predatory scarring on humpback whales (Megaptera novaeangliae) in east Australian waters. Wildl Res 31:163-170

Otway NM (2015) Serum biochemical reference intervals for freeliving sand tiger sharks (Carcharias taurus) from east Australian waters. Vet Clin Pathol 44:262-274

Powell RA, Proulx G (2003) Trapping and marking terrestrial mammals for research: integrating ethics, performance criteria, techniques, and common sense. ILAR J 44:259-276

Pratt HL, Carrier JC (2001) A review of elasmobranch reproductive behavior with a case study on the nurse shark, Ginglymostoma cirratum. Environ Biol Fish 60:157-188

Skomal GB (2007) Evaluating the physiological and physical consequences of capture on post-release survivorship in large pelagic fishes. Fish Manag Ecol 14:81-89

Smith M (1992) Capture and transportation of elasmobranchs, with emphasis on the grey nurse shark (Carcharias taurus). Mar Freshw Res 43:325-343 
Strong WB, Stanitski CL, Dyment PG, Smith RE, Dembert M, Keith JF (1986) Evaluating the potential pediatric scuba diver. Am J Dis Child 140:1135-1141

Thompson RKR, Foltin RW, Boylan RJ, Sweet A, Graves CA, Lowitz CE (1981) Tonic immobility in Japanese quail can reduce the probability of sustained attack by cats. Anim Learn Behav 9:145-149

Voegeli FA, Smale MJ, Webber DM, Andrade Y, O'Dor RK (2001) Ultrasonic telemetry, tracking and automated monitoring technology for sharks. Environ Biol Fish 60:267-281

Watsky MA, Gruber SH (1990) Induction and duration of tonic immobility in the lemon shark, Negaprion brevirostris. Fish Physiol Biochem 8:207-210

Wells RMG, McNeil H, MacDonald JA (2005) Fish hypnosis: induction of an atonic immobility reflex. Mar Freshw Behav Physiol 38:71-78
Weng KC, Block BA (2004) Diel vertical migration of the bigeye thresher shark (Alopias superciliosus), a species possessing orbital retia mirabilia. Fish Bull 102:221-229

Whitman PA, Marshall JA, Keller EC (1986) Tonic Immobility in the Smooth Dogfish Shark, Mustelus canis (Pisces, Carcharhinidae). Copeia 1986:829-832

Wilks J (2000) Scuba Diving and Snorkeling Safety on Australia's Great Barrier Reef. J Travel Med 7:283-299

Williamson MJ, Kavanagh AS, Noad MJ, Kniest E, Dunlop RA (2016) The effect of close approaches for tagging activities by small research vessels on the behavior of humpback whales (Megaptera novaeangliae). Mar Mamm Sci 32: 1234-1253 